\title{
DEMOGRAPHIC AND SOCIO-ECONOMIC SITUATION OF THE NOMADIC POPULATION OF CHERVLENY YAR AREA IN THE MIDDLE OF THE $14^{\mathrm{TH}}$ CENTURY
}

\author{
Aleksandr P. Nikitin \\ Voronezh State University, Voronezh, Russian Federation
}

\begin{abstract}
The article attempts to identify the probable number of people who could have lived in the DonKhoper interfluve in the middle of the $14^{\text {th }}$ century. The results of demographic observations are based on natural resources, historical and archaeological realities of the region, special characteristics of nomadic economy.

The area between the Don and the Khoper in the middle of the $14^{\text {th }}$ century was an administrative unit of the ulus of Jochi (the Horde). The information about the territorial entity was preserved in the Metropolitan Charters for Sarai and Ryazan eparchies. Thanks to contemporary archaeological studies of this area, the nomadic and sedentary population can be claimed to have existed in that area in the middle of the $14^{\text {th }}$ century. The nomadic territory of Chervleny Yar was bounded by the Don in the West, by Khoper in the East, by the mouth of the Hopper in the South, and by the most northern nomadic burials of that period. The information about natural resources of the steppes can be the basis of the demographic model designed. The data of ethnology, history, archaeology and ecology are used as a basis. The author analyzes the provision of the nomads with food as biological resources of the ecosystem between the Don and the Khoper rivers.

To calculate the probable number of the population, the author takes into account the health calorie intake, the average number of livestock per person in nomadic communities, the size of territory under consideration and the availability of forage for livestock. All the data for calculating the number of population are collected in the Table.

Possible number of nomadic population of the Chervleny Yar in the middle of the $14^{\text {th }}$ century can make 26,042-69,444 people, on the condition of the minimum possible yield and optimal load on the ecosystem between the Don and the Khoper. The indicated number refers to the group of the population that never left the area between the Don and the Khoper and conducted their economy in the confines of the specified bounds. The calculations do not take into account possible migration and other demographic factors. This attempt of counting is preliminary and purely hypothetical.

Key words: socio-economic development, Chervleny Yar, Horde, the Jochi Ulus, demographics, population, the Middle Don Area, Don-Khoper interfluve.

Citation. Nikitin A.P. Demographic and Socio-Economic Situation of the Nomadic Population of Chervleny Yar Area in the Middle of the $14^{\text {th }}$ Century. Vestnik Volgogradskogo gosudarstvennogo universiteta. Serija 4, Istorija. Regionovedenie. Mezhdunarodnye otnoshenija [Science Journal of Volgograd State University. History. Area Studies. International Relations], 2017, vol. 22, no. 4, pp. $40-45$ (in Russian). DOI: https://doi.org/ 10.15688/jvolsu4.2017.4.4
\end{abstract}

\section{ДЕМОГРАФИЧЕСКОЕ И СОЦИАЛЬНО-ЭКОНОМИЧЕСКОЕ ПОЛОЖЕНИЕ} КОЧЕВОГО НАСЕЛЕНИЯ ЧЕРВЛЕНОГО ЯРА В СЕРЕДИНЕ XIV ВЕКА

\author{
Александр Петрович Никитин \\ Воронежский государственный университет, г. Воронеж, Российская Федерация
}


Аннотация. В статье делается попытка определить вероятное количество населения, которое могло бы проживать в междуречье Дона и Хопра в середине XIV века. В основу результатов демографических наблюдений положены природные ресурсы края, исторические и археологические реалии региона, особенности ведения кочевого хозяйства.

Междуречье Дона и Хопра в середине XIV в. было административной единицей улуса Джучи (Орды). Информация об этом территориальном образовании сохранилась в грамотах митрополитов для Сарайской и Рязанской епархий. Благодаря современному изучению данной территории археологами можно уверенно говорить о наличии на этой территории в середине XIV в. кочевого и оседлого населения. Территория кочевания Червленого Яра ограничена Доном с запада, Хопром с востока, устьем Хопра с юга и наиболее северными погребениями кочевников этого периода. На основе информации о природных запасах степей можно построить демографическую модель. В качестве базиса используются данные этнологии, истории, археологии, экологии. В основе построений лежит обеспеченность продуктами питания кочевников посредством использования биозапасов экосистемы междуречья Дона и Хопра.

Для расчета вероятного количества населения используется медицинская норма потребления калорий, среднее количество скота на одного человека в кочевых обществах, площадь рассматриваемой территории и наличие кормовой базы для скота. Все данные для подсчета численности населения собраны в таблице.

Возможную численность кочевого населения Червленого Яра в середине XIV в. можно определить в пределах 26 042-69 444 человек при условии минимальной возможной урожайности и оптимальной нагрузки на экосистему междуречья Дона и Хопра. Указанная численность относится к группе населения, которая не покидает междуречье Дона и Хопра и ведет свое хозяйство в пределах указанных границ. Также подсчеты не учитывают возможные миграционные процессы и прочие демографические факторы. Данная попытка подсчета является предварительной и носит гипотетический характер.

Ключевые слова: социально-экономическое развитие, Червленый Яр, Орда, улус Джучи, демография, население, Средний Дон, междуречье Дона и Хопра.

Цитирование. Никитин А. П. Демографическое и социально-экономическое положение кочевого населения Червленого Яра в середине XIV века // Вестник Волгоградского государственного университета. Серия 4, История. Регионоведение. Международные отношения. - 2017. - T. 22, № 4. - C. 40-45. - DOI: https://doi.org/ 10.15688/jvolsu4.2017.4.4

Червленый Яр - одна из административных единиц Джучидского государства (Золотой Орды), занимающая пространство междуречья Дона и Хопра (значительная часть современной Воронежской области, а также Волгоградской). Стала известна в XIV в. благодаря грамотам митрополитов Сарайской и Рязанской епархий. В грамотах (1334-1353 гг. и около 1360 г.) указаны различные категории населения, проживавшие в указанных границах [4]. Однако до сих пор все попытки выстроить социально-экономическую модель в междуречье Дона и Хопра базировались только на косвенных данных, без прибегания к реконструкции демографических процессов, без определения податного населения и экономического потенциала.

На левобережье Дона, в его среднем течении, известно множество золотоордынских погребений: грунтовые, курганные могильники, а также погребения, связанные с архитектурномонументальными сооружениями (мавзолеями). Помимо погребальных памятников, известны поселенческие памятники с золотоордынской и русской керамикой. Археологические памятни- ки являются материальным подтверждением проживания в Червленом Яре постоянного как кочевого населения, так и оседлого [7, с. 168]. Датировка грамот совпадет с периодом стабильности в Орде, предшествующей замятне. Северная граница проживания кочевого населения маркируется наиболее северными погребениями кочевников золотоордынского периода. Это территория лесостепи, скорее всего, на широте современного Каширского района Воронежской области; именно здесь были раскопаны наиболее северные золотоордынские погребения Олень-Колодец [2]. Другими северными погребениями могут считаться курганные погребения в Прихоперье [1].

Лесные массивы, ограничивающие пространство кочевания на Дону с севера, отмечены в записках Гильома де Рубрука: «Упомянутая река имеет также на западном берегу большой лес» [3, с. 109-110]. По всей видимости, речь про лесные массивы, которые располагаются на границе степи и лесостепи. К тому же в археологическом плане четко фиксируется этническая принадлежность Верхнего Подонья 
(территории севернее устья реки Воронеж) к древнерусскому населению [7, с. 168].

Таким образом, территория кочевания ограничена Доном с запада, Хопром с востока, южная точка - это устье Хопра, а северные территории кочевания могут быть связаны с северными районами Воронежской области. Площадь кочевания в указанных границах может быть определена в 25000 30000 кв км. Зная исходную площадь, используемую для обеспечения жизни кочевого населения, можно рассчитать экологические запасы степей-лесостепей Червленого Яра. При условии, что в середине XIV в. не было массовых миграций и население Червленого Яра было примерно постоянным, можно попытаться установить вероятное количество населения. Для определения вероятного количества населения, которое могло бы проживать на данной территории, используя пространство междуречья Дона и Хопра в качестве кочевий, применяются эколого-демографические наработки археологов и этнологов А.А. Тортики, В.К. Михеева, Р.И. Кортиева (Р.И. Куртиев). Статья построена на физико-географических особенностях экосистем, продуктивности пастбищ, необходимом рационе кочевой семьи и отдельного ее члена, опыте различных кочевых обществ всего Великого пояса степей. Исследователи использовали наработки различныХ этнологов XIX-XX вв., которые изучали кочевников древности и средневековья и получили статистические данные по количеству человек в семье, количеству скота по разным видам на хозяйство, количеству скота на одного человека, индексу обеспеченности продуктами питания. Все построения сделаны с учетом проживания в одинаковых природно-географических зонах, консервативности кочевых социальных и экономических систем, где, как выделяют авторы, «кочевник активно и целеустремленно использует землю как средство производства: он прекрасно осведомлен о продуктивности пастбищ и качестве кормов на них, постоянно следит за соблюдением рационального цикла перекочевок, не позволяет скоту стравливать травы больше, чем это может выдержать пастбище, бережет во все остальные сезоны неприкосновенность зимнего пастбища». В публикации [5] авторы использовали формулу Б.А. Быкова для определения количества скота, которое может пережить зиму, используя биозапасы зимних пастбищ. Усредненные статистические данные по ряду показателей сводятся к тому, что в семье пять человек; голов скота на семью - 95,8 (это 203,5 условных овец); голов скота на человека - 19,6 (40,7 условных овец); ИОП $=1,13$, что соответствует экологической обеспеченности 2370 ккал на человека в сутки, то есть почти медицинская норма. С модернизированной методикой подсчета, а также с аргументацией авторов можно ознакомиться в статье «Методика эколого-демографического исследования традиционных кочевых обществ Евразии» [6].

Переходя к необходимым нам расчетам, будем иметь в виду, что на одного кочевника требуется условное количество скота, которое обеспечивает его необходимыми килокалориями. Данное количество скота потребляет определенное количество условных кормовых единиц. Биозапасы территорий ограничены. Для кочевых нужд можно получить только определенное количество кормовой базы. Ключевым в данных подсчетах будет территория зимних кочевий, которая обычно занимает от 30 до 50 \% от общей территории кочевания. При этом с зимних кочевий в нормальных условиях потребляется 30-50 \% кормовой базы, потребление 70-80 \% кормовой базы - это уже чрезвычайное состояние экосистемы. Именно биозапасы зимних кочевий и ограничивают количество единиц скота в стаде. Если определить площадь зимних кочевий, то можно узнать максимальное количество стада, которое кормится на этой территории в зимний период. Для этого потребуется знать минимальную возможную урожайность территорий. Для расчетов было обозначено 500 кормовых единиц с 1 га. В свою очередь, одна овца потребляет от 0,5 до 1,5 кормовых единиц. В среднем значении это одна кормовая единица на одну условную овцу. После этого требуется вернуться к началу данных построений и разделить максимальное количество стада на условное количество скота, требующееся на одного кочевника. Так будет получена приблизительная численность населения, способная вести кочевое хозяйство на данной территории. Считается, что на одного кочевника в год требуется минимум 36 условных овец. Все данные сведены в единую таблицу. 
А.П. Никитин. Демографическое и социально-экономическое положение кочевого населения Червленого Яра

\section{Сводная таблица расчета природно-демографических возможностей} кочевого населения Червленого Яра

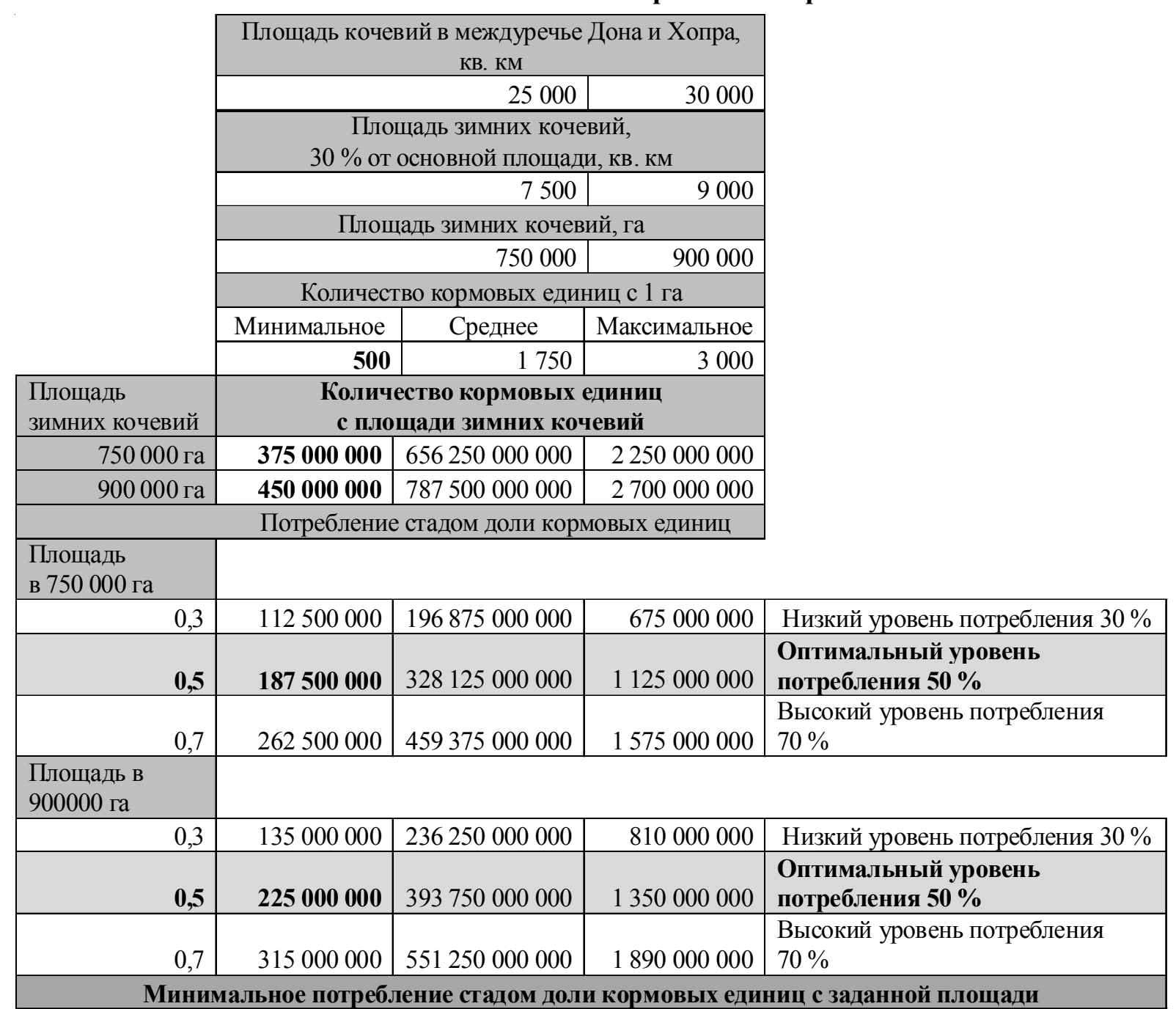

Минимальное потребление стадом доли кормовых единиц с заданной площади \begin{tabular}{r|r|}
187500000 & 225000000 \\
\hline
\end{tabular}

Количество потребления кормовых единиц одной условной овцой в условную зиму

\begin{tabular}{|c|c|c|c|}
\hline & 90 & 150 & 200 \\
\hline & \multicolumn{3}{|c|}{$\begin{array}{c}\text { Вероятный размер стада на заданной } \\
\text { территории }\end{array}$} \\
\hline 187500000 & 2083333,3 & 1250000 & 937500 \\
\hline \multirow[t]{4}{*}{225000000} & 2500000 & 1500000 & 1125000 \\
\hline & \multicolumn{3}{|c|}{$\begin{array}{c}\text { Определяем количество вероятного кочевого } \\
\text { населения в междуречье Дона и Хопра }\end{array}$} \\
\hline & 57870 & 34722 & 26042 \\
\hline & 69444 & 41667 & 31250 \\
\hline
\end{tabular}

Таким образом, возможную численность кочевого населения Червленого Яра в середине XIV в. можно определить в приделах $26042-$ 69444 человек при условии минимальной возможной урожайности и оптимальной нагрузки на экосистему междуречья Дона и Хопра. Указанная численность относится к группе насе- ления, которая не покидает междуречье Дона и Хопра и ведет свое хозяйство в пределах названных границ. В случае сезонной откочевки к более южным территориям, например, на Нижний Дон, будут требоваться иные демографические и социальные построения. Подсчеты не учитывают возможные миграционные 
процессы, а также прочие демографические и социальные факторы. Данная попытка подсчета является предварительной и носит гипотетический характер. На основе полученных данных в дальнейшем можно говорить о заселенности территории, налоговой базе, коммуникациях, экономическом потенциале отдельной административной единицы улуса Джучи и т. д.

\section{СПИСОК СОКРАЩЕНИЙ} питания.

ИОП - индекс обеспеченности продуктами

\section{СПИСОК ЛИТЕРАТУРЫ}

1. Березуцкий, В. Д. Новые данные о поздних кочевниках из левобережья Среднего Дона / В. Д. Березуцкий // Исследования памятников археологии Восточной Европы. - Воронеж : Изд-во Воронеж. гос. пед. ун-та, 1988. - С. 152-165.

2. Ефимов, К. Ю. Золотоордынские погребения из могильника «Олень-Колодезь» / К. Ю. Ефимов // Российская археология. -2000. - № 1.-С. 167-181.

3. Путешествия в восточные страны Плано Карпини и Рубрука / ред., вступ. ст. и примеч. Н. П. Шастиной. - М. : Гос. изд-во геогр. лит., 1957. $270 \mathrm{c}$.

4. Селезнёв, Ю. В. Церковная политика митрополита Алексия на ордынской территории: спор между Рязанской и Сарайской епархиями о юрисдикции в междуречье Дона и Хопра / Ю. В. Селезнёв // Первые церковно-исторические Митрофановские чтения. - Воронеж : Полиарт, 2012. - С. 26-32.

5. Тортика, А. А. Некоторые эколого-демографические и социальные аспекты истории кочевых обществ / А. А. Тортика, В. К. Михеев, Р. И. Кортиев // Этнографическое обозрение. - 1994. - № 1. C. 49-61.

6. Тортика, А. А. Методика эколого-демографического исследования традиционных кочевых обществ Евразии / А. А. Тортика, В. К. Михеев // Археология восточноевропейской лесостепи. Вып. 15. Средневековые древности евразийских степей. - Воронеж : Изд-во Воронеж. гос. ун-та, 2001.C. 141-161.

7. Цыбин, М. В. Периферия Золотой Орды в Подонье / М. В. Цыбин // Краткие сообщения Института археологии / Институт археологии РАН. М. : Наука, 2007. - Вып. 221. - С. 166-175.

\section{REFERENCES}

1. Berezutsky V.D. Novye dannye o pozdnikh kochevnikakh iz levoberezhya Srednego Dona [New Data on Late Nomads from the Left Bank of the Middle Don]. Issledovaniya pamyatnikov arkheologii Vostochnoy Evropy [Researches of monuments of archeology of Eastern Europe]. Voronezh, 1988, pp. 152-165.

2. Efimov K.Yu. Zolotoordynskie pogrebeniya iz mogilnika «Olen-Kolodez» [Golden Horde Burials from Burial Mound Olen-Kolodez]. Rossiyskaya arkheologiya, 2000, no. 1, pp. 167-181.

3. Shastina N.P. Puteshestviya v vostochnye strany Plano Karpini i Rubruka [Travels to Eastern Countries of Plano Carpini and Rubruca]. Moscow, Gos. izd-vo geogr. lit., 1957. 270 p.

4. Seleznev Yu.V. Tserkovnaya politika mitropolita Aleksiya na ordynskoy territorii: spor mezhdu Ryazanskoy i Sarayskoy eparkhiyami o yurisdiktsii v mezhdurechye Dona i Khopra [Church Policy of Metropolitan Alexy in the Horde Territory: the Dispute between the Ryazan and Sarai Dioceses about Jurisdiction in the Interfluve of the Don and the Khoper]. Pervye tserkovno-istoricheskie Mitrofanovskie chteniya [First Church-Historic Mitrofanov's Readings]. Voronezh, 2012, pp. 26-32.

5. Tortika A.A., Mikheev V.K., Kortiev R.I. Nekotorye ekologo-demograficheskie i sotsialnye aspekty istorii kochevykh obshchestv [Some Ecological and Demographic and Social Aspects of the History of Nomadic Societies]. Etnograficheskoe obozrenie, 1994, no. 1, pp. 49-61.

6. Tortika A.A., Mikheev V.K. Metodika ekologo-demograficheskogo issledovaniya traditsionnykh kochevykh obshchestv Evrazii [Technique of Ecological and Demographic Research of Traditional Nomadic Societies of Eurasia]. Arkheologiya vostochnoevropeyskoy lesostepi. Vyp. 15. Srednevekovye drevnosti evraziyskikh stepey [The Archaeology of the East-European Forest-Steppe. Iss. 15: Medieval Antiquities of Eurasian Steppes]. Voronezh, Izd-vo Voronezh. gos. un-ta, 2001, pp. 141-161.

7. Tsybin M.V. Periferiya Zolotoy Ordy v Podonye [Periphery of the Golden Horde in the Don Region]. Kratkie soobshcheniya Instituta arkheologii / Institut arkheologii RAN [Brief Reports of Institute of Archaeology / Institute of Archaeology of RAS]. Moscow, Nauka Publ., 2007, vol. 221, pp. 166-175. 
А.П. Никитин. Демографическое и социально-экономическое положение кочевого населения Червленого Яра

\section{Information about the Author}

Aleksandr P. Nikitin, Postgraduate Student, Department of History of Russian, Voronezh State University, Prosp. Moskovsky, 88, 394068 Voronezh, Russian Federation, niksonvrn@gmail.com, http:// orcid.org/0000-0003-0799-0767

\section{Информация об авторе}

Александр Петрович Никитин, аспирант кафедры истории России, Воронежский государственный университет, Московский просп., 88, 394068 г. Воронеж, Российская Федерация, niksonvrn@gmail.com, http://orcid.org/0000-0003-0799-0767 